\title{
DETERMINATION OF ACETIC AND PROPANOIC ACIDS CONCENTRATION IN NIGERIAN KEROSENE
}

\author{
ISAAC KAYODE ADEGUN ${ }^{* 1}$, OLUWATOSIN ADEDAMOLA ADESOYE ${ }^{1}$, \\ ADIO-YUSUF SELIA IYAGBA ${ }^{2}$, DAVID ADEBOLA ADETORO ${ }^{1}$
}

\author{
${ }^{I}$ Department of Mechanical Engineering, Faculty of Engineering and Technology, \\ University of Ilorin, Ilorin, Kwara State, Nigeria \\ ${ }^{2}$ Department of Civil Engineering, Faculty of Engineering and Technology, University of \\ Ilorin, Ilorin, Kwara State, Nigeria
}

\begin{abstract}
The paper aims to determine acetic and propanoic acid concentrations in some selected samples of kerosene used in Nigeria. The Armfield Liquid-Liquid Extraction Unit was employed to carry out the study. Distilled water and kerosene samples from five different sources were used for the investigation. The parameters taken into consideration during the course of the experiments were time, thermal conductivity, temperature, flow rates and concentration of the acid. It was deduced from the research that the temperature and the conductivity decreased with significant decrease in concentration of the acid and vice versa. The results gotten from the extraction of the kerosene samples also showed that sample A, sample D, and sample E did not contain acetic acid while sample B and sample C had traces of acetic acid, with sample $\mathrm{C}$ having traces of propanoic acid. After comparing the values with the standard classification of acetic acid, it was discovered that the concentration of both acetic and propanoic acid in the samples were not significantly sufficient to harm human beings.
\end{abstract}

Keywords: Acetic acid, propanoic acid, kerosene, concentration

\section{INTRODUCTION}

Kerosene, otherwise known as paraffin lamp oil and coal oil is commonly used as fuel in the aviation industries and households [1]. It is a flammable and clear liquid obtained from hydrocarbon as a result of fractional distillation of petroleum between $150{ }^{\circ} \mathrm{C}$ and $300{ }^{\circ} \mathrm{C}$, resulting in a mixture with a density of $0.78-0.81 \mathrm{~g} / \mathrm{cm}^{3}$ [2]. It is miscible with petroleum solvents but immiscible with water. It has a pale yellow color and it can also be a colorless oily liquid which has an unpleasant odor [3].

According to Adelaja et al. [4], kerosene is one of the most widely demanded petroleum product in Nigeria. It is used as a fuel in stoves for domestic cooking and also used as a light source during power failure in both the rural and urban areas of Nigeria. As a light source, it is predominantly used in the homes of low income earners (both the educated and uneducated people). For this reason, there is a need to investigate the level of acetic and propanoic acid concentration in the kerosene used in Nigeria because of its negative effects on man.

\footnotetext{
* Corresponding author, email: kadegun@ unilorin.edu.ng; oluwatosinadesoye@ yahoo.com

(C) 2019 Alma Mater Publishing House
} 
Kerosene can be used as a solvent in pesticides for killing insects such as head lice and bed bugs. It could also be applied to stagnant pools of water to kill mosquito larvae by preventing the exchange of oxygen. Also, adhesives left by stickers on glass surfaces can be removed by applying kerosene [5]. Acetic acid in its undiluted state is sometimes called glacial acetic acid. Acetic acid tastes distinctively sour and has a pungent smell, propanoic acid also known as propionic acid or methylacetic acid is also known to be harmful to human's health due to its corrosive effects [6].

According to Niosh [7], acetic and acetic acid with increased concentration is corrosive to the skin and should be handled carefully to avoid skin burns, permanent eye damage, and irritation to the mucous membranes. Prolonged exposure of the skin with glacial acetic acid could result in the destruction of the tissue. Exposure (for about eight hours) to vapours of acetic acid or propanoic acid at about $10 \mathrm{ppm}$ can cause irritation of the eyes, nose, and the throat while at about $100 \mathrm{ppm}$, it can lead to lungs irritation and possible damage to the lungs, eyes, and skin. Sheretz [8] stated that when exposed to vapour concentrations of about 1,000 ppm, it can cause marked irritation of the eyes, nose, and upper respiratory tract. He also asserted that exposure to $50 \mathrm{ppm}$ or more cannot be tolerated by most people and can cause intensive lacrimation and irritation of the eyes, nose, and throat causing pharyngeal oedema and chronic bronchitis. He discovered that the effects of solutions of acetic acid on humans depend on its concentration.

Many researchers had also carried out works on different constituents of kerosene and how the concentrations of these constituents influence its use. Gonzalo et al. [9] carried out a flow-injection analysis to determine the phenolic compounds in kerosene and naphtha by membrane extraction (pre-concentration). The kerosene and naphtha samples were obtained from an oil company in Nigeria. Reagents used include a stock solution of phenol, 4-ammoantlpyrme solution, and an oxidant solution. A Hewlett Packard 8452A diode array was used to monitor the reaction at a wavelength of $500 \mathrm{~nm}$.

Venkatramani and Phillips [10] investigated two-dimensional gas chromatography for the analysis of complex petroleum mixtures and kerosene. This was done to determine the various constituents and their concentrations. A Vanan Model 3700 gas chromatograph equipped with a flame ionization detector was used for the analysis. Fernandez et al. [11] also carried out an analysis similar to the one of Ganzalo et al. [9]. They adopted the continuous membrane extraction coupled with chromatographic analysis for the determination of phenols in fuels (gasoline and kerosene). It was observed in their work that the concentrations of phenols varied slightly even though the samples were gotten from the same source

Due to the likely effects of sulfur on the environment, some researchers investigated how sulfur could be extracted from non-hydro-treated kerosene. Sobati et al. [12] carried out an experimental study on the desulfurization of non-hydro-treated kerosene and stated that non-hydro-treated kerosene had a feedstock with a total sulfur content of 2335 ppmw. Owing to the corrosion problems that naphthenic acids do cause during oil refinery, there has been increasing interest in acidic fractions in crude oil. Colati et al. [13] monitored the liquidliquid extraction of naphthenic acids in Brazilian crude oil. The acidic number measurement was performed using a potentiometer while the sulfur content was determined using an SLFA-2800 Energy Dispersive X-ray Fluorescence Spectrometer. Lissitsyna et al. [6] conducted an investigation to determine n-paraffins, isoparaffins, olefins-naphthenes and aromatics (PIONA) in kerosene samples by comprehensive two-dimensional gas chromatography.

According to the American Society of Testing and Materials (ASTM), there are two grades of kerosene which are -1-k (low sulfur content) and 2-k, both acceptable for use in the household [14]. These grades are dependent on the impurity content especially sulfur and aromatics which reduces its efficiency and increases the toxic emissions during combustion [15]. -1-k kerosene has no more than $0.04 \%$ sulfur by weight while 2-k has no more than $0.30 \%$.

In the present study, liquid-liquid extraction was used. This involves the transfer of one or more solute present in a feed solution to a solvent which is an immiscible liquid. The solvent containing the solute is called the extract while the solution from which the solute is transferred is called the raffinate. It is used to separate different compounds based on their relative solubility into two different immiscible liquids. It usually involves using water and an organic solvent. It is the transfer of a substance from one liquid phase to another. The physical and chemical processes involved in liquid-liquid extraction is called partitioning. 
Although acetic acid and propanoic acid are classified as weak acids [16], at some certain level of concentrations, they are corrosive and can attack the skin if they are not handled with appropriate care and can also cause irritation to the mucous membrane (International Programme on Chemical Safety, 2010) [15]. Having noted these implications, the researcher deemed it fit to search into acetic acid and propanoic acid concentration levels from different kerosene sources in Nigeria.

\section{EXPERIMENTAL SETUP}

\subsection{Methodology}

Kerosene samples were obtained from Oando Petroleum Company, Mobil Petroleum Company, Total Petroleum Company, Nigerian National Petroleum Corporation (NNPC) and BOVAS. Armfield UOP5-MKII LiquidLiquid Extraction Unit shown in Figure 1 was used to conduct the experiment.

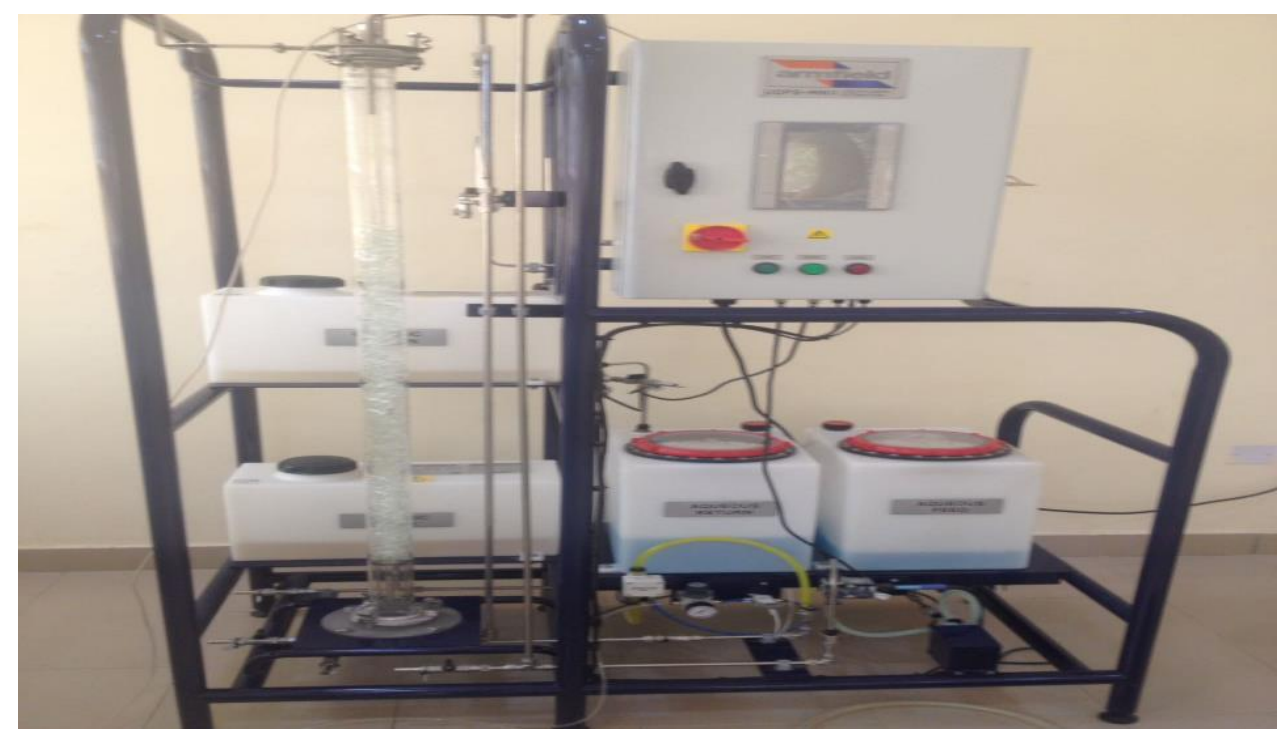

Fig. 1. Liquid-Liquid extraction unit.

pH Meter (HM Digital, PH-200) shown in Figure 2 was used to determine the pH values of both the organic feed (kerosene) and the organic return.

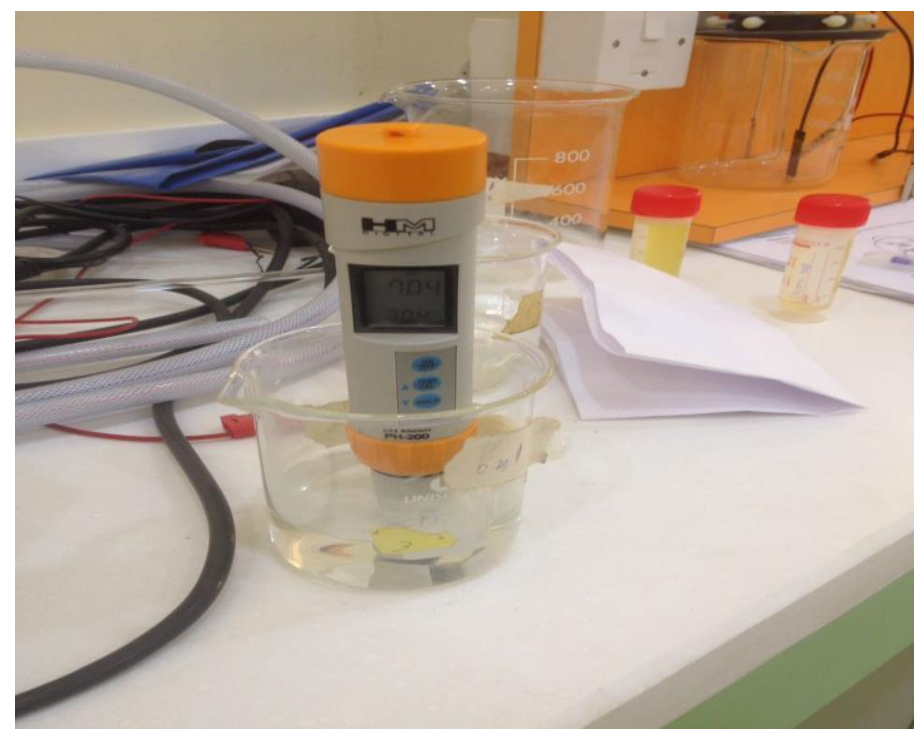

Fig. 2. $\mathrm{pH}$ meter placed in a beaker.

\subsubsection{Experimental Procedures for Liquid-Liquid Extractor}


The organic feed tank was filled with $5 \mathrm{~L}$ of kerosene and sufficient amount of water soluble dye (armfield blue dye) was added to 10 litres of distilled water to lightly color the water. This enabled the visualization of the two fluids inside the column. The aqueous feed tank was filled with $10 \mathrm{~L}$ of distilled water to which a water soluble dye has been added. $\mathrm{V}_{\text {INT }}$ was fully closed for a phase change to occur at the top of the column. The aqueous priming button was then switched on to activate the aqueous pump (P1) so as to partly fill the extraction column to the top of the rashig rings with distilled water. The organic priming button was turned on to activate the organic pump (P2) so as to fill the extraction column with droplets of kerosene that would rise through the water and accumulate above the water. When the column was filled to the top plate and the organic phase starts to fill the organic return tank, the pump was switched off using the organic priming button. The flow rate for the organic pump was set at $80 \mathrm{~mL} / \mathrm{min}$ while the aqueous pump was set at $160 \mathrm{~mL} / \mathrm{min}$. To obtain the conductivity of the aqueous phase and the transfer of acetic acid from the kerosene, the software supplied with UOP5-MKII Liquid-Liquid Extraction Unit was used.

\subsubsection{Experimental Procedures for $\mathrm{pH}$ Test}

$100 \mathrm{~mL}$ of distilled water was poured into a beaker and the buffer solution was prepared by pouring a buffer capsule for $\mathrm{pH} 7$ into the distilled water. The $\mathrm{pH}$ meter was placed in the beaker and the calibration was done when the $\mathrm{pH}$ reached 7.0. The solution to be tested was then placed in the $\mathrm{pH}$ meter [17].

\subsubsection{Determination of total Acid Extracted}

The volume of acid extracted can be evaluated using equation 1 .

where,

$$
\mathrm{V}_{\mathrm{E}}=\mathrm{V}_{\mathrm{A}} \mathrm{Y}
$$

$\mathrm{V}_{\mathrm{A}}$ - flow rate of aqueous phase in $\mathrm{L} / \mathrm{s}$;

$\mathrm{V}_{\mathrm{E}}$ - volume of the acid extracted in $\mathrm{kg} / \mathrm{s}$;

$\mathrm{Y}-$ acid concentration in the aqueous phase in $\mathrm{kg} / \mathrm{L}$.

$$
Y=\sum_{8}^{1} W_{i}, i=1,2,3, \ldots 8
$$

where, $i$ is the elapsed time, $\mathrm{W}$ - concentration of the acid (W1 and W2).

\section{RESULTS AND DISCUSSION}

Five samples of kerosene labeled A, B, C, D, and E (this arrangement does not follow the above mentioned companies) were experimentally examined through extraction processes. Four extraction processes were carried out on each of the samples examined and the average values were recorded.

$\mathrm{T}$ in column 1 of Table 1 is the elapsed time at which parameters of interest such as conductivity of the aqueous feed (C1), conductivity of the aqueous return (C2), temperature of the aqueous feed (T1), temperature of the aqueous return (T2), organic flow rate $\left(\mathrm{F}_{\mathrm{o}}\right)$, water/aqueous flow rate $\left(\mathrm{F}_{\mathrm{w}}\right)$, concentration of the acetic acid (W1) and concentration of the propanoic acid (W2) were examined. It could be depicted from Table 1 that for $0 \leq \mathrm{T} \leq$ 6:00; C1, C2, T1, T2, $\mathrm{F}_{\mathrm{o}}, \mathrm{F}_{\mathrm{w}}, \mathrm{W} 1$, and $\mathrm{W} 2$ had almost constant values. For $6<\mathrm{T} \leq 8: 00 ; \mathrm{C} 2$ and $\mathrm{W} 2$ were decreasing with increasing elapsed time while $\mathrm{C} 1$ was almost constant throughout the elapsed time of the extraction. C2 remained constant for the first 5:30mins and then increased till it attained its maximum point at 6:30 min before it started to fall. This is an indication that as the conductivity of the aqueous return reduced, the temperature and concentration of the propanoic acid also reduced. This predicts that for a short elapsed time, temperature of the aqueous return does not have an impact on the concentration but as the elapsed time grew, the temperature of the aqueous return started to have an effect on the concentration. 
Table 1. Kerosene Analysis for the Extraction Process of Sample A.

\begin{tabular}{|rrrrrrrrr|}
\hline T $[m i n s]$ & $\mathrm{C} 1[\mu \mathrm{S} / \mathrm{cm}]$ & $\mathrm{C} 2[\mu \mathrm{S} / \mathrm{cm}]$ & $\mathrm{T} 1\left[{ }^{\circ} \mathrm{C}\right]$ & $\mathrm{T} 2\left[{ }^{\circ} \mathrm{C}\right]$ & $\mathrm{Fo}[\mathrm{L} / \mathrm{min}]$ & $\mathrm{Fw}[\mathrm{L} / \mathrm{min}]$ & $\mathrm{W} 1[\%]$ & W2[\%] \\
\hline $00: 00$ & 30.15 & 62.88 & 29.20 & 29.70 & 80.00 & 160.00 & 0.00 & 0.01 \\
\hline $00: 30$ & 30.15 & 63.00 & 29.20 & 29.70 & 80.00 & 160.00 & 0.00 & 0.01 \\
\hline $01: 00$ & 30.03 & 62.88 & 29.20 & 29.70 & 80.00 & 160.00 & 0.00 & 0.01 \\
\hline $01: 30$ & 30.15 & 63.00 & 29.20 & 29.70 & 80.00 & 160.00 & 0.00 & 0.01 \\
\hline $02: 00$ & 30.15 & 63.00 & 29.20 & 29.70 & 80.00 & 160.00 & 0.00 & 0.01 \\
\hline $02: 30$ & 30.03 & 63.00 & 29.20 & 29.70 & 80.00 & 160.00 & 0.00 & 0.01 \\
\hline $03: 00$ & 30.03 & 63.00 & 29.20 & 29.70 & 80.00 & 160.00 & 0.00 & 0.01 \\
\hline $03: 30$ & 30.03 & 63.00 & 29.20 & 29.70 & 80.00 & 160.00 & 0.00 & 0.01 \\
\hline $04: 00$ & 30.03 & 63.00 & 29.20 & 29.70 & 80.00 & 160.00 & 0.00 & 0.01 \\
\hline $04: 30$ & 30.03 & 63.12 & 29.20 & 29.70 & 80.00 & 160.00 & 0.00 & 0.01 \\
\hline $05: 00$ & 30.03 & 63.12 & 29.20 & 29.70 & 80.00 & 160.00 & 0.00 & 0.01 \\
\hline $05: 30$ & 30.03 & 63.12 & 29.20 & 29.70 & 80.00 & 160.00 & 0.00 & 0.01 \\
\hline $06: 00$ & 30.03 & 63.24 & 29.20 & 29.70 & 80.00 & 160.00 & 0.00 & 0.01 \\
\hline $06: 30$ & 30.03 & 64.71 & 29.20 & 29.70 & 80.00 & 160.00 & 0.00 & 0.01 \\
\hline $07: 00$ & 29.91 & 45.05 & 29.20 & 30.00 & 80.00 & 160.00 & 0.00 & 0.00 \\
\hline $07: 30$ & 30.03 & 36.63 & 29.20 & 29.89 & 80.00 & 160.00 & 0.00 & 0.00 \\
\hline $08: 00$ & 29.91 & 34.92 & 29.20 & 29.80 & 80.00 & 160.00 & 0.00 & 0.00 \\
\hline
\end{tabular}

It can also be observed from Table 2 that for $0 \leq \mathrm{T} \leq 8: 00 ; \mathrm{T} 1, \mathrm{~T} 2, \mathrm{~F}_{\mathrm{o}}, \mathrm{F}_{\mathrm{w}}$, and $\mathrm{W} 1$ had constant values while $\mathrm{C} 1$ was gradually and sparingly increasing with $\mathrm{T}$. For $0 \leq \mathrm{T} \leq 3: 30 ; \mathrm{C} 2$ and $\mathrm{W} 2$ had almost a constant value while for $4.00 \leq \mathrm{T} \leq 8: 00 ; \mathrm{C} 2$ and $\mathrm{W} 2$ were decreasing with increase in elapsed time. This is an indication that as the conductivity of the aqueous return decreased, the concentration (W2) also decreased. This shows that for a short elapsed time, the conductivity of the aqueous return does not have a significant impact on the concentration. As the elapsed time grew the conductivity of the aqueous return began to have a significant effect on the concentration.

Table 2. The Kerosene Analysis for the Extraction Process of Sample B.

\begin{tabular}{|rrrrrrrrr|}
\hline T $[$ mins $]$ & $\mathrm{C} 1[\mu \mathrm{S} / \mathrm{cm}]$ & $\mathrm{C} 2[\mu \mathrm{S} / \mathrm{cm}]$ & $\left.\mathrm{T} 1{ }^{\circ} \mathrm{C}\right]$ & $\mathrm{T} 2\left[{ }^{\circ} \mathrm{C}\right]$ & $\mathrm{Fo}[\mathrm{L} / \mathrm{min}]$ & $\mathrm{Fw}[\mathrm{L} / \mathrm{min}]$ & $\mathrm{W} 1[\%]$ & W2[\%] \\
\hline $00: 00$ & 154.82 & 227.96 & 30.10 & 30.50 & 80.00 & 160.00 & 0.04 & 0.49 \\
\hline $00: 30$ & 154.94 & 227.96 & 30.20 & 30.50 & 80.00 & 160.00 & 0.04 & 0.49 \\
\hline $01: 00$ & 154.94 & 228.08 & 30.10 & 30.50 & 80.00 & 160.00 & 0.04 & 0.49 \\
\hline $01: 30$ & 154.94 & 228.32 & 30.10 & 30.50 & 80.00 & 160.00 & 0.04 & 0.50 \\
\hline $02: 00$ & 154.94 & 228.44 & 30.10 & 30.50 & 80.00 & 160.00 & 0.04 & 0.50 \\
\hline $02: 30$ & 155.06 & 228.57 & 30.10 & 30.50 & 80.00 & 160.00 & 0.04 & 0.50 \\
\hline $03: 00$ & 155.06 & 228.57 & 30.10 & 30.50 & 80.00 & 160.00 & 0.04 & 0.50 \\
\hline $03: 30$ & 155.06 & 228.69 & 30.10 & 30.50 & 80.00 & 160.00 & 0.04 & 0.50 \\
\hline $04: 00$ & 155.06 & 213.43 & 30.10 & 30.50 & 80.00 & 160.00 & 0.04 & 0.40 \\
\hline $04: 30$ & 155.18 & 171.30 & 30.10 & 30.50 & 80.00 & 160.00 & 0.04 & 0.20 \\
\hline $05: 00$ & 155.31 & 162.02 & 30.10 & 30.60 & 80.00 & 160.00 & 0.04 & 0.17 \\
\hline $05: 30$ & 155.31 & 158.48 & 30.10 & 30.50 & 80.00 & 160.00 & 0.04 & 0.16 \\
\hline $06: 00$ & 155.31 & 157.14 & 30.10 & 30.50 & 80.00 & 160.00 & 0.04 & 0.15 \\
\hline $06: 30$ & 155.31 & 156.65 & 30.10 & 30.50 & 80.00 & 160.00 & 0.04 & 0.15 \\
\hline $07: 00$ & 155.43 & 155.92 & 30.10 & 30.50 & 80.00 & 160.00 & 0.04 & 0.15 \\
\hline $07: 30$ & 155.43 & 155.43 & 30.10 & 30.50 & 80.00 & 160.00 & 0.04 & 0.15 \\
\hline $08: 00$ & 155.55 & 155.31 & 30.10 & 30.50 & 80.00 & 160.00 & 0.04 & 0.15 \\
\hline
\end{tabular}


Figure 3 is a plot showing the variation of conductivity with elapsed time. It can be seen from the graph that the value of conductivity $\mathrm{C} 1$ remained almost constant throughout the elapsed time of the extraction. $\mathrm{C} 2$ remained almost a constant value but there was a sudden drop in its value between elapsed time of 3:30 min and 5:30 min. After an elapsed time of 5:30 min, the conductivities $\mathrm{C} 1$ and $\mathrm{C} 2$ almost attained the same value. This was as a result of the steadiness achieved by the concentration of the two fluids.

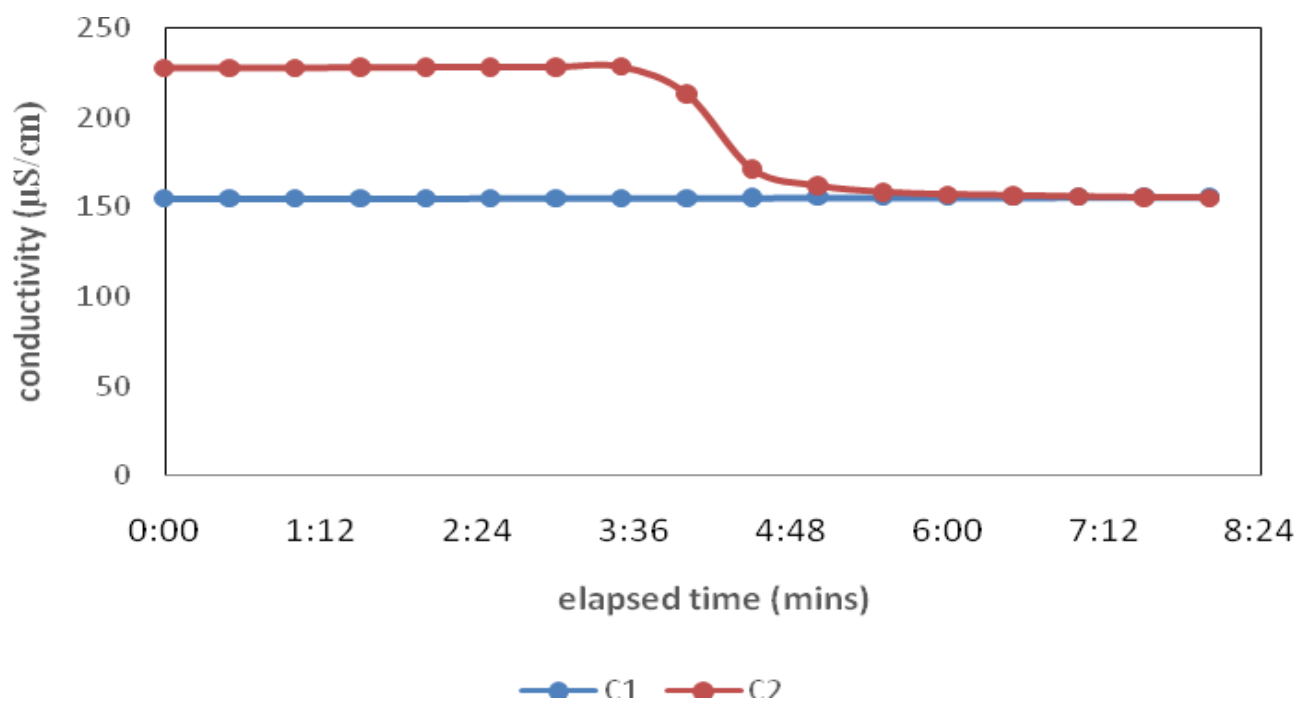

Fig. 3. Graph of conductivity against elapsed time (Sample B).

Figure 4 shows a steep change in concentration of W2 between elapsed time of 3:30 min and 4:30 min after which the concentration remained stable. Observation of Figures $3 \& 4$ shows that the elapsed time of 3:30 min to 4:30 min was a transition period and it was after this period of time that the concentrations of the two acids achieved a constant value.

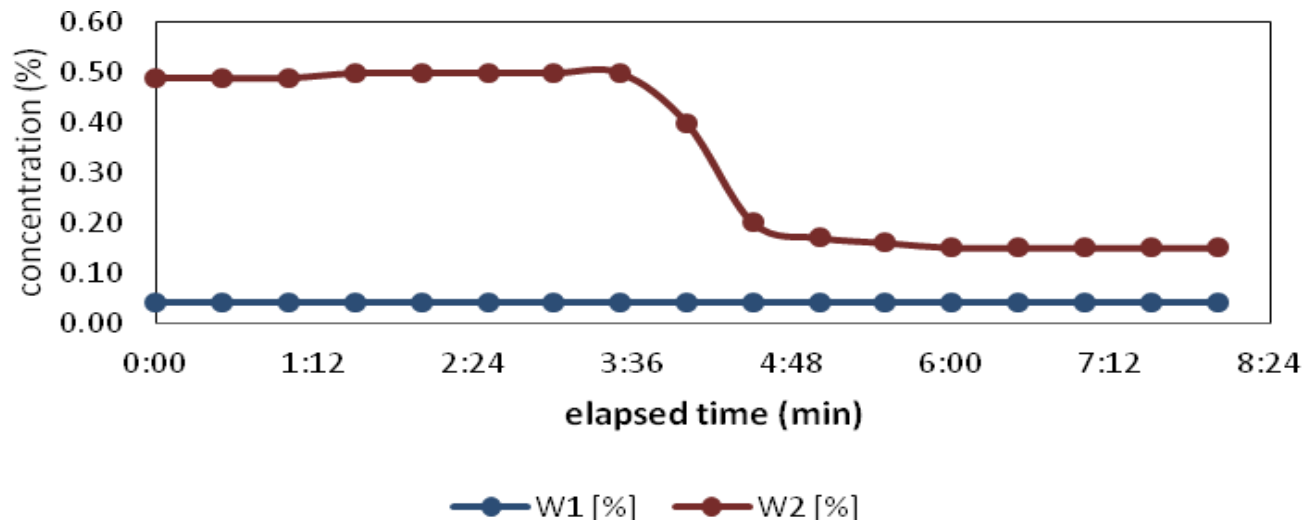

Fig. 4. Graph of concentration against elapsed time (Sample B).

It could be observed from Table 3 that for $0 \leq \mathrm{T} \leq 8: 00 ; \mathrm{T} 1, \mathrm{~F}_{\mathrm{o}}, \mathrm{F}_{\mathrm{w}}$, and $\mathrm{W} 1$ had constant values while $\mathrm{C} 1$ sparingly increased. For $0 \leq \mathrm{T} \leq 4: 30$ and 5:30 $\leq \mathrm{T} \leq 8: 00$; $\mathrm{T} 2$ had two different constant values. The table also shows that the conductivity of the aqueous return had significant impact on the concentration of W2. This was because; as C2 reduced, W2 also reduced and vice versa. 
Table 3. Analysis of the Extraction Process of Sample C.

\begin{tabular}{|lllllllll|}
\hline $\mathrm{T}[\mathrm{mins}]$ & $\mathrm{C} 1[\mu \mathrm{S} / \mathrm{cm}]$ & $\mathrm{C} 2[\mu \mathrm{S} / \mathrm{cm}]$ & $\mathrm{T} 1\left[{ }^{\circ} \mathrm{C}\right]$ & $\mathrm{T} 2\left[{ }^{\circ} \mathrm{C}\right]$ & $\mathrm{F} 0[\mathrm{~L} / \mathrm{min}]$ & $\mathrm{Fw}[\mathrm{L} / \mathrm{min}]$ & $\mathrm{W} 1[\%]$ & $\mathrm{W} 2[\%]$ \\
\hline $00: 00$ & 151.52 & 442.00 & 29.39 & 29.60 & 80.00 & 160.00 & 0.04 & 3.95 \\
\hline $00: 30$ & 151.64 & 442.24 & 29.39 & 29.60 & 80.00 & 160.00 & 0.04 & 3.96 \\
\hline $01: 00$ & 151.89 & 442.49 & 29.39 & 29.60 & 80.00 & 160.00 & 0.04 & 3.97 \\
\hline $01: 30$ & 152.38 & 442.73 & 29.39 & 29.60 & 80.00 & 160.00 & 0.04 & 3.98 \\
\hline $02: 00$ & 151.89 & 442.97 & 29.39 & 29.60 & 80.00 & 160.00 & 0.04 & 3.98 \\
\hline $02: 30$ & 151.77 & 443.10 & 29.39 & 29.60 & 80.00 & 160.00 & 0.04 & 3.99 \\
\hline $03: 00$ & 151.77 & 443.34 & 29.39 & 29.60 & 80.00 & 160.00 & 0.04 & 3.99 \\
\hline $03: 30$ & 151.77 & 443.58 & 29.39 & 29.60 & 80.00 & 160.00 & 0.04 & 4.00 \\
\hline $04: 00$ & 151.77 & 443.71 & 29.39 & 29.60 & 80.00 & 160.00 & 0.04 & 4.00 \\
\hline $04: 30$ & 151.89 & 437.60 & 29.39 & 29.60 & 80.00 & 160.00 & 0.04 & 3.83 \\
\hline $05: 00$ & 151.89 & 375.09 & 29.39 & 29.70 & 80.00 & 160.00 & 0.04 & 2.36 \\
\hline $05: 30$ & 152.01 & 311.59 & 29.39 & 29.80 & 80.00 & 160.00 & 0.04 & 1.32 \\
\hline $06: 00$ & 152.01 & 275.21 & 29.39 & 29.80 & 80.00 & 160.00 & 0.04 & 0.89 \\
\hline $06: 30$ & 152.01 & 246.64 & 29.39 & 29.80 & 80.00 & 160.00 & 0.04 & 0.63 \\
\hline $07: 00$ & 152.01 & 211.47 & 29.39 & 29.80 & 80.00 & 160.00 & 0.04 & 0.39 \\
\hline $07: 30$ & 152.13 & 189.86 & 29.39 & 29.80 & 80.00 & 160.00 & 0.04 & 0.28 \\
\hline $08: 00$ & 152.25 & 179.85 & 29.39 & 29.80 & 80.00 & 160.00 & 0.04 & 0.23 \\
\hline & & & & & & & & \\
\hline
\end{tabular}

Table 4 shows that for $0 \leq \mathrm{T} \leq 4: 00 ; \mathrm{T} 2, \mathrm{~F}_{\mathrm{o}}, \mathrm{F}_{\mathrm{w}}, \mathrm{W} 1$, and $\mathrm{W} 2$ had almost constant values; $\mathrm{C} 2$ was unstable while $\mathrm{C} 1$ and $\mathrm{T} 1$ tried to increase. For 4:30 $\leq \mathrm{T} \leq 8: 00$; $\mathrm{C} 2$ decreased with increasing elapsed time while W2 dropped in value and remained constant with increasing elapsed time. The table also reveals that, for this sample, it took time before the conductivity of returns had an impact on the concentration of the acids.

Table 4. Kerosene Analysis for the Extraction Process of Sample D.

\begin{tabular}{|llllllllll|}
\hline $\mathrm{T}[\mathrm{mins}]$ & $\mathrm{C} 1[\mu \mathrm{S} / \mathrm{cm}]$ & $\mathrm{C} 2[\mu \mathrm{S} / \mathrm{cm}]$ & $\mathrm{T} 1\left[{ }^{\circ} \mathrm{C}\right]$ & $\mathrm{T} 2\left[{ }^{\circ} \mathrm{C}\right]$ & $\mathrm{Fo}[\mathrm{L} / \mathrm{min}]$ & $\mathrm{Fw}[\mathrm{L} / \mathrm{min}]$ & $\mathrm{W} 1[\%]$ & $\mathrm{W} 2[\%]$ \\
\hline $00: 00$ & 6.95 & 91.45 & 26.80 & 27.20 & 80.00 & 160.00 & 0.00 & 0.03 \\
\hline $00: 30$ & 6.95 & 91.45 & 26.80 & 27.20 & 80.00 & 160.00 & 0.00 & 0.03 \\
\hline $01: 00$ & 6.95 & 91.57 & 26.89 & 27.20 & 80.00 & 160.00 & 0.00 & 0.03 \\
\hline $01: 30$ & 6.59 & 91.57 & 26.80 & 27.20 & 80.00 & 160.00 & 0.00 & 0.03 \\
\hline $02: 00$ & 6.47 & 91.57 & 26.80 & 27.20 & 80.00 & 160.00 & 0.00 & 0.03 \\
\hline $02: 30$ & 6.34 & 91.57 & 26.70 & 27.20 & 80.00 & 160.00 & 0.00 & 0.03 \\
\hline $03: 00$ & 6.34 & 91.69 & 26.70 & 27.20 & 80.00 & 160.00 & 0.00 & 0.03 \\
\hline $03: 30$ & 6.34 & 91.57 & 26.70 & 27.20 & 80.00 & 160.00 & 0.00 & 0.03 \\
\hline $04: 00$ & 6.34 & 91.69 & 26.70 & 27.20 & 80.00 & 160.00 & 0.00 & 0.03 \\
\hline $04: 30$ & 6.34 & 56.65 & 26.70 & 27.10 & 80.00 & 160.00 & 0.00 & 0.01 \\
\hline $05: 00$ & 6.34 & 56.04 & 26.70 & 27.10 & 80.00 & 160.00 & 0.00 & 0.01 \\
\hline $05: 30$ & 6.34 & 55.18 & 26.70 & 27.10 & 80.00 & 160.00 & 0.00 & 0.01 \\
\hline $06: 00$ & 6.22 & 54.33 & 26.70 & 27.10 & 80.00 & 160.00 & 0.00 & 0.01 \\
\hline $06: 30$ & 6.34 & 53.96 & 26.70 & 27.10 & 80.00 & 160.00 & 0.00 & 0.01 \\
\hline $07: 00$ & 6.22 & 53.72 & 26.70 & 27.10 & 80.00 & 160.00 & 0.00 & 0.01 \\
\hline $07: 30$ & 6.22 & 53.60 & 26.70 & 27.10 & 80.00 & 160.00 & 0.00 & 0.01 \\
\hline $08: 00$ & 6.22 & 53.47 & 26.70 & 27.10 & 80.00 & 160.00 & 0.00 & 0.01 \\
\hline & & & & & & & & \\
\hline
\end{tabular}


Figure 5 is a plot showing the variation of conductivity with elapsed time. C1 was almost constant throughout the elapsed time of the extraction. C2 remained constant for the first 4:00 min, dropped at 4:30 min, and then remained constant for the rest of the elapsed period.

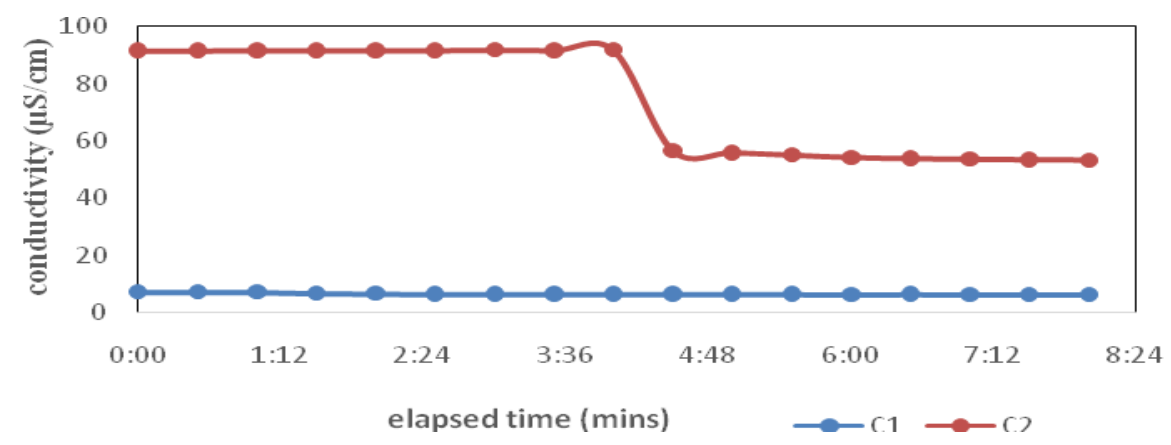

Fig. 5. Graph of conductivity against elapsed time (Sample D).

Figure 6 is a plot depicting the variation of temperature with elapsed time. T1 fluctuated for the first 2:30 min before it stabilised for the rest of the elapsed period. T2 remained constant till it reached 4.00 min when it dropped slightly and then became constant for the remaining time left.

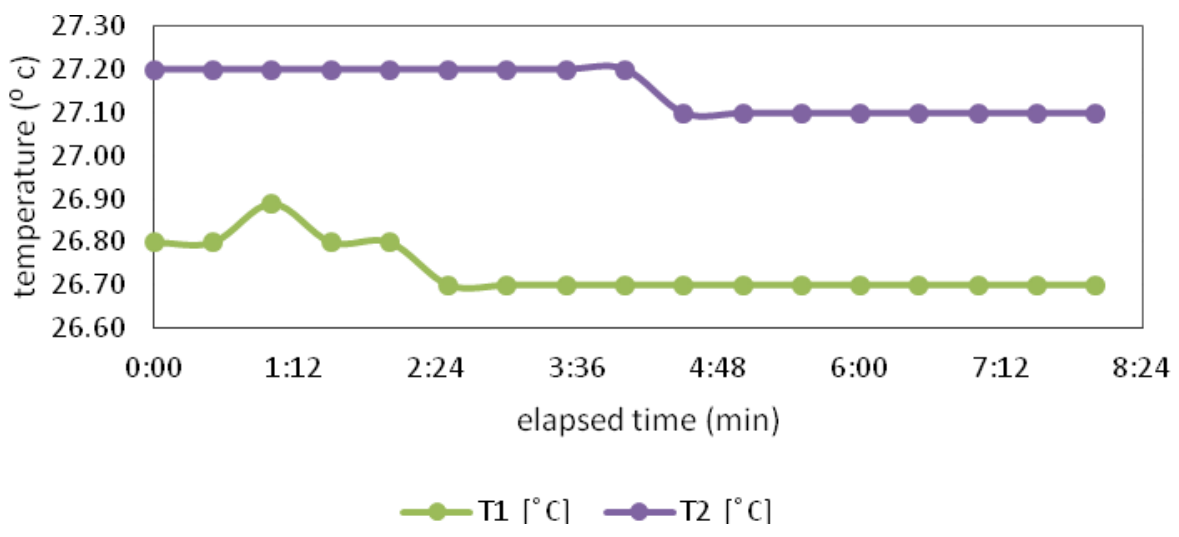

Fig. 6. Graph of temperature against elapsed time (Sample D).

Figure 7 is a plot indicating variation of concentration with elapsed time. W1 remained constant throughout the elapsed time. W2 remained constant for the first 4:00 min, reduced and afterwards remained constant till the end of the elapsed time.

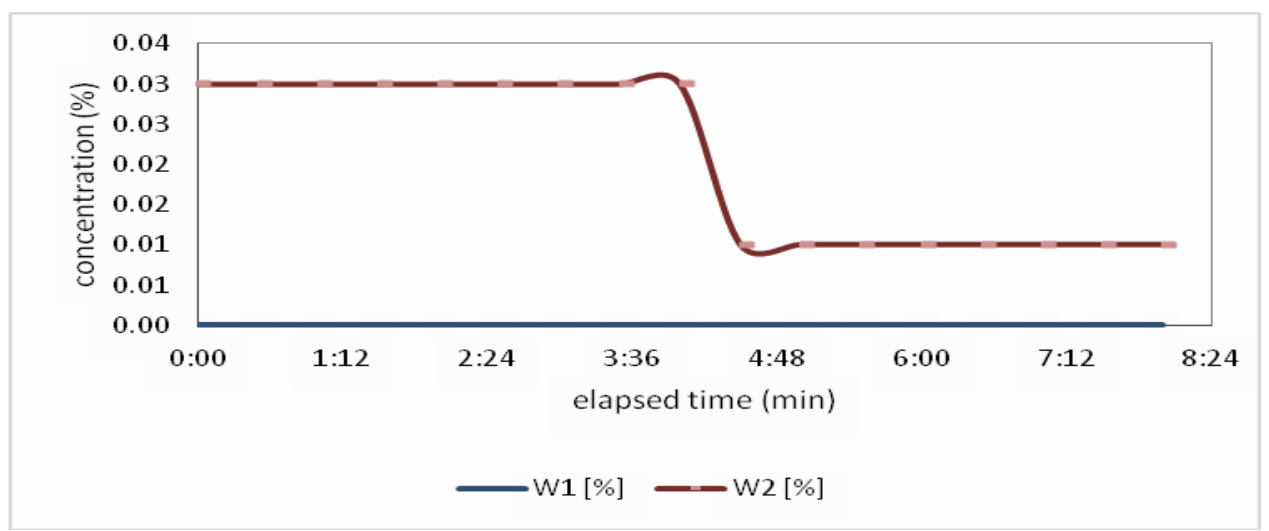

Fig. 7. Variation of concentration with elapsed time (Sample D). 
It can be observed from the Table 5 that for $0 \leq \mathrm{T} \leq 8: 00 ; \mathrm{C} 1, \mathrm{C} 2, \mathrm{~T} 1$, and $\mathrm{T} 2$ have almost constant values while for $0 \leq \mathrm{T} \leq 8: 00 ; \mathrm{F}_{\mathrm{o}}, \mathrm{F}_{\mathrm{w}}, \mathrm{W} 1$, and $\mathrm{W} 2$ were constant.

This is an indication that the conductivity, temperature and concentration of the aqueous return remained constant. This shows that for the elapsed time, temperature of the aqueous return did not have an effect on the concentration.

Table 5. Kerosene Analysis for the Extraction Process of Sample E.

\begin{tabular}{|lrrrrrrrr|}
\hline $\mathrm{T}[\mathrm{min}]$ & $\mathrm{C} 1[\mathrm{HS} / \mathrm{cm}]$ & $\mathrm{C} 2[\mu \mathrm{S} / \mathrm{cm}]$ & $\mathrm{T} 1\left[{ }^{\circ} \mathrm{C}\right]$ & $\mathrm{T} 2\left[{ }^{\circ} \mathrm{C}\right]$ & $\mathrm{Fo}[\mathrm{L} / \mathrm{min}]$ & $\mathrm{Fw}[\mathrm{L} / \mathrm{min}]$ & $\mathrm{W} 1[\%]$ & $\mathrm{W} 2[\%]$ \\
\hline $00: 00$ & 6.95 & 48.22 & 27.00 & 27.30 & 80.00 & 160.00 & 0.00 & 0.00 \\
\hline $00: 30$ & 6.95 & 48.22 & 27.00 & 27.30 & 80.00 & 160.00 & 0.00 & 0.00 \\
\hline $01: 00$ & 6.83 & 48.10 & 26.89 & 27.30 & 80.00 & 160.00 & 0.00 & 0.00 \\
\hline $01: 30$ & 6.95 & 48.22 & 27.00 & 27.30 & 80.00 & 160.00 & 0.00 & 0.00 \\
\hline $02: 00$ & 6.83 & 48.10 & 26.89 & 27.39 & 80.00 & 160.00 & 0.00 & 0.00 \\
\hline $02: 30$ & 6.83 & 48.10 & 26.89 & 27.30 & 80.00 & 160.00 & 0.00 & 0.00 \\
\hline $03: 00$ & 6.83 & 48.22 & 26.89 & 27.30 & 80.00 & 160.00 & 0.00 & 0.00 \\
\hline $03: 30$ & 6.95 & 48.22 & 26.89 & 27.39 & 80.00 & 160.00 & 0.00 & 0.00 \\
\hline $04: 00$ & 6.83 & 48.22 & 26.89 & 27.39 & 80.00 & 160.00 & 0.00 & 0.00 \\
\hline $04: 30$ & 6.95 & 48.22 & 26.89 & 27.39 & 80.00 & 160.00 & 0.00 & 0.00 \\
\hline $05: 00$ & 6.83 & 48.10 & 26.89 & 27.39 & 80.00 & 160.00 & 0.00 & 0.00 \\
\hline $05: 30$ & 6.95 & 48.10 & 26.89 & 27.39 & 80.00 & 160.00 & 0.00 & 0.00 \\
\hline $06: 00$ & 6.83 & 48.10 & 26.89 & 27.39 & 80.00 & 160.00 & 0.00 & 0.00 \\
\hline $06: 30$ & 6.95 & 48.10 & 26.89 & 27.39 & 80.00 & 160.00 & 0.00 & 0.00 \\
\hline $07: 00$ & 6.83 & 48.10 & 26.89 & 27.39 & 80.00 & 160.00 & 0.00 & 0.00 \\
\hline $07: 30$ & 6.83 & 47.98 & 26.89 & 27.39 & 80.00 & 160.00 & 0.00 & 0.00 \\
\hline $08: 00$ & 6.83 & 47.98 & 26.89 & 27.39 & 80.00 & 160.00 & 0.00 & 0.00 \\
\hline
\end{tabular}

Figure 8 is a plot showing a variation of conductivity with elapsed time. $\mathrm{C} 1$ and $\mathrm{C} 2$ were almost constant throughout the elapsed time of the extraction.

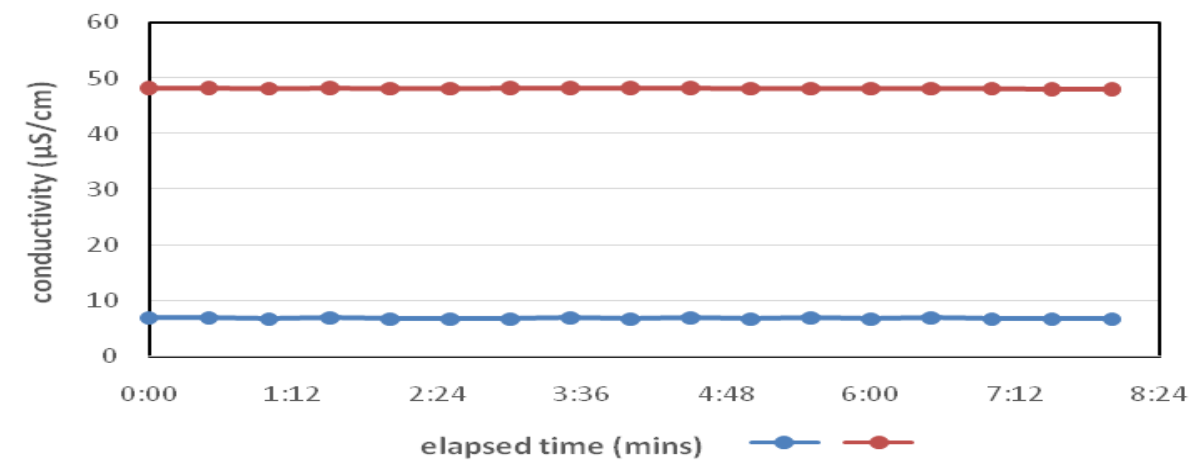

Fig. 8. Graph of conductivity against elapsed time (Sample E).

Figure 9 is a plot depicting the variation of temperature with elapsed time. T1 fluctuated for 2:00 min before it stabilised for the rest of the elapsed period. T2 remained constant initially for the first 1:30 min, and then fluttered till it reached 3:30 min before it stabilised for the remaining elapsed period. 


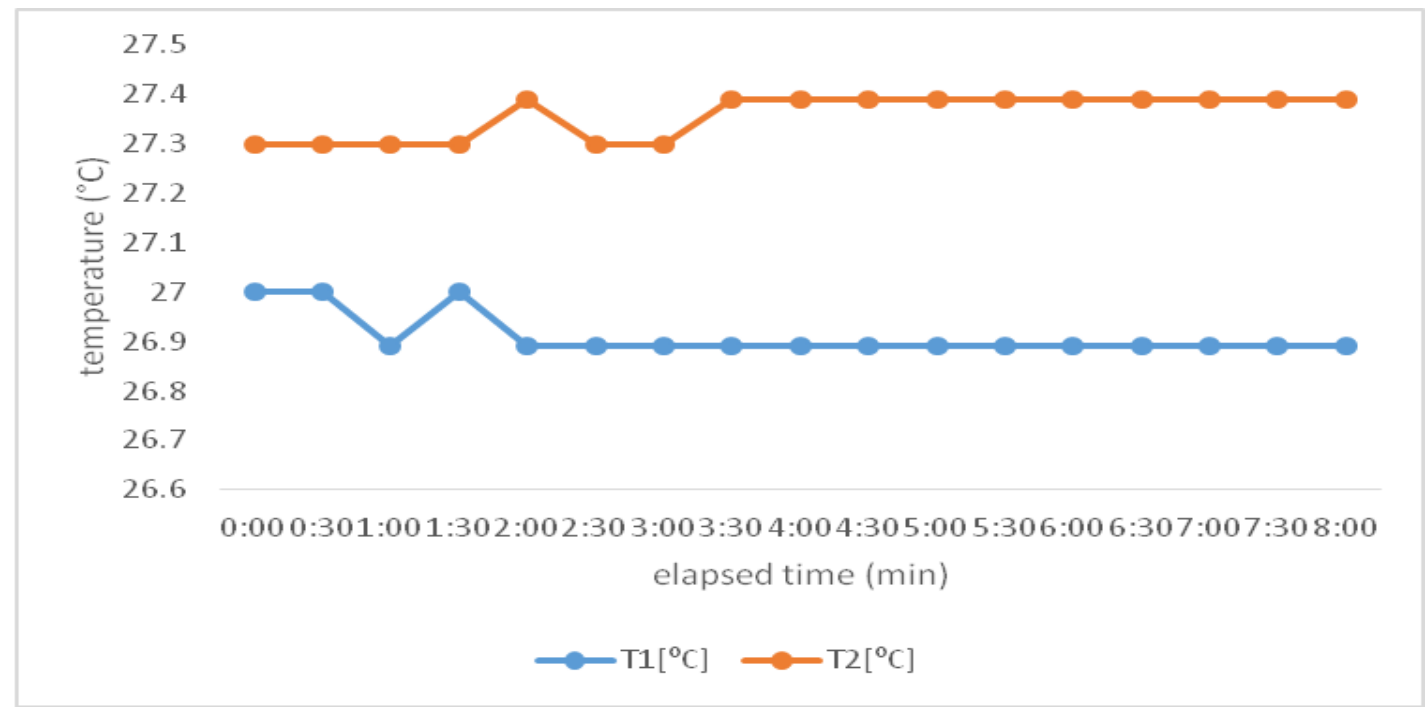

Fig. 9. Graph of temperature against elapsed time (Sample E).

Table 6. Classification of Acetic Acid Concentration in Various Samples.

Name of Sample

Concentration (\%)

\section{Classification}

\begin{tabular}{lll}
\hline SAMPLE A & 0.00 & less than $10 \%$, not an irritant \\
\hline SAMPLE B & 0.68 & less than $10 \%$, not an irritant \\
\hline SAMPLE C & 0.68 & less than $10 \%$, not an irritant \\
\hline SAMPLE D & 0.00 & less than $10 \%$, not an irritant \\
\hline SAMPLE E & 0.00 & less than $10 \%$, not an irritant \\
\hline
\end{tabular}

Table 6 shows that acetic acid was only present in two of the samples and the concentration of the acid present was not up to the recommended $10 \%$ that can cause significant harm to the human health and in Table 7 the $\mathrm{pH}$ of samples.

Table 7. $\mathrm{pH}$ of the Samples.

\begin{tabular}{|ccc|}
\hline Samples & $\mathbf{p H}$ of feed & pH of raffinate \\
\hline SAMPLE A & 6.97 & 10.26 \\
\hline SAMPLE B & 6.76 & 11.25 \\
\hline SAMPLE C & 6.56 & 10.64 \\
\hline SAMPLE D & 6.92 & 10.53 \\
\hline SAMPLE E & 9.24 & 10.82 \\
\hline
\end{tabular}

\section{CONCLUSIONS}

The liquid-liquid extraction unit is an equipment which was used to study the mass transfer of acetic acid and propanoic acid concentration from kerosene into water. The sensor incorporated in the machine measures the conductivity and temperature and then uses it to determine the concentration of the acid transferred. It was deduced that the temperature and the conductivity decreased with significant decrease in concentration of the acid and vice versa. Samples A, D, and E did not contain acetic acid while samples B and C have traces of acetic acid but not up to the standard specification of $10 \%$ that could cause harm to humans and animals. Trace of propanoic acid was also highest in sample $\mathrm{C}$.

\section{Acknowledgement}

The authors appreciate Nigerian National Petroleum Corporation (NNPC) for donating NLG Research Laboratory to the Faculty of Engineering and Technology, University of Ilorin, Ilorin, Nigeria. The effort of the staff members of the laboratory during the course of the study is also acknowledged. 


\section{REFERENCES}

[1] Guralink, D.B., Friend, J.H., Webster's new world college dictionary, Associated Press, New York, 2014.

[2] Collins, C.D., Implementing phytoremediation of petroleum hydrocarbons, methods; phytoremediation: methods and reviews (ed.: Willey, N.), Webster's New World College Dictionary, Associated Press, New York, 2014.

[3] Curl, H., O’Donnell, K., Chemical and physical properties of refined petroleum products (NOAA Technical Memorandum ERL MESA-17), NOAA, Colorado, 1977.

[4] Adelaja, A.O., Taiwo, B.A., Lashore, B.O., Forecasting local consumption of dual purpose kerosene (dpk) in Nigeria, International Conference on Infrastructure Development and the Environment (ICIDEN2006), Abuja, Nigeria, 10-15 September, 2006.

[5] Chilcott, R.P., Compendium of chemical hazards: kerosene (fuel oil), CHAD HQ, United Kingdom, 2006.

[6] Lissitsyna, K., Huertas, S., Quintero, L.C., Polo, L.M., PIONA Analysis of fuel by comprehensive twodimensional gas chromatography couple to time of flight mass spectrometry, Fuel, vol. 116, 2014, p. 716-722.

[7] CDC-NIOSH pocket guide to chemical hazards-acetic acid, NIOSH Press, United States of America, 1992. http://www.cdc.gov/niosh/npg.

[8] Sherertz, P.C., Acetic acid, department of health hazards control, Virginia, 1994, https://virginia.gov/epidemilogy/DEE/PublicHealthToxiclogy/documents/aceticacid

[9] Gonzalo, E.R., Pavon, J.L.P., Ruzicka, J., Christian, G.D., Olson, D.C., Flow injection analysis determination of phenols in kerosene and naphtha by membrane extraction, Analytica Chimica Acta, vol. 259, 1991, p. $37-44$.

[10] Venkatramani, C.J., Philips, J.B., Comprehensive two dimensional gas chromatography applied to the analysis of complex mixtures, Journal of Microcolumn Separations, vol. 5, 1993, p. 511-516.

[11] Femandez Laespada, M.E., Pavon, J.L.P., Cordero, B.M., Continuous membrane extraction coupled with chromatographic analysis for the determination of phenols in fuels, Journal of Chromatography, vol. 823, 1998, p. 537-548.

[12] Sobati, M.A., Dehkordi, A.M., Shahrokhi, M., Liquid-liquid extraction of oxidized sulfur-containing compounds of non-hydrotreated kerosene, Fuel Processing Technology, vol. 91, no. 11, 2010, p. 1386-1394.

[13] Colati, K.A.P., Dalmaschio, G.P., De Castro, E.V.R., Gomes, A.O., Vaz, B.G., Romao, W., Monitoring the liquid/liquid extraction of naphthenic acids in Brazilian crude oil using electrospray ionization FT-ICR Mass Spectrometry, Fuel, vol. 108, 2013, p. 647-655.

[14] Acetic Acid, Available from: https://en.wikipedia.org/wiki/Acetic_Acid

[15] ICSC 0363- Acetic acid, International Programme on Chemical Safety, 5 June 2010.

[16] Bates, R.G., Determination of pH: Theory and practice, Wiley, New York, 1973.

[17] Feldman, I., Use and abuse of pH measurements, Analytical Chemistry, vol. 28, 1956, p. 1859-1866. 